\section{A review of safety incidents in England and Wales for vascular endothelial growth factor inhibitor medications}

\begin{abstract}
Purpose To learn from patient safety incidents (PSIs) following recent introduction of vascular endothelial growth factor inhibitor medications (anti-VEGF) in ophthalmic care, as reported via a national incident reporting database.

Methods Thematic retrospective review of anti-VEGF medications PSIs as reported via clinical incident reporting methods in NHS care in England and Wales from 2003 to 2010, ascertained from database mining at the National Patient Safety Agency (NPSA). Results In all, 166 relevant anti-VEGF incidents were reported. Reports have increased year on year from 2006. Incident severity as reported: 10 were reported as 'severe harm' and 23 as 'moderate harm'. The remainder were 'low' or 'no harm' events. The incident themes and/or causes found and by order of severity included: intra-ocular inflammation/endophthalmitis $(n=16)$; treatment or follow-up delays $(n=45)$; wrong medication ( $n=26)$; wrong eye/patient injection $(n=17)$; missing records $(n=12)$. Other problems included medication availability and refrigeration failures. We reflect on potential solutions for addressing the matters found. Systemic safety matters, stroke, subdural hemorrhage, and myocardial infarction (total $n=3$ ) followed anti-VEGF treatments.

Conclusion Although infrequent, anti-VEGF medication PSIs or errors do occur and are thus a threat to quality. This review also provides supporting evidence to existing concerns and challenges surrounding age-related macular degeneration service
\end{abstract}

Royal Bolton Hospital NHS Foundation Trust,

Lancashire, UK

Correspondence: SP Kelly, Royal Bolton Hospital NHS Foundation Trust, Minerva Road, Farnworth, Bolton BL4 OJR, England, UK Tel: + 441204 390694; Fax: +44 1204390442

Received: 28 February 2011 Accepted: 8 March 2011 Published online: 29 April 2011

Presented at 2011 Annual Scientific Congress of the Royal College of Ophthalmologists. pressures and provision. Lessons for improvement of care from a national incident reporting database for a frequently undertaken and recently introduced ophthalmic procedure were found. Suggestions are proposed for improving quality by reducing such problems based on analysis of such reports. Endophthalmitis reports following intra-vitreal injections suggest rigorous infection control measures are required.

Eye (2011) 25, 710-716; doi:10.1038/eye.2011.89; published online 29 April 2011

Keywords: vascular endothelial growth factor; macular; retina; patient safety incident; endophthalmitis; organization

Introduction

Age-related macular degeneration (AMD) is the leading cause of blindness in developed economies. Neovascular or wet-AMD accounts for more than half of all cases of registered sight and severe sight impairment, and approximately 26000 new cases of wet-AMD develop every year in the UK. ${ }^{1,2}$ There have been major recent advances in the treatment of wet-AMD with the use of biological agents and in particular with vascular endothelial growth factor (VEGF) inhibitor medications frequently termed 'anti-VEGF agents' following publication of key trial results. ${ }^{3-5}$ These studies showed that wet-AMD patients treated with frequent (monthly or 6 weekly) intra-vitreal injections of anti-VEGF agents had a greatly reduced risk of visual loss compared with no treatment or other existing treatments. 
Interim guidelines on the use of anti-VEGF agents based on these key trials were published in $2006 .^{6}$ The Royal College of Ophthalmologists (the College) provided guidance on provision of AMD services in 2007. ${ }^{7}$ By August 2008, the National Institute for Health and Clinical Excellence (NICE) advised the NHS that such treatment with the anti-VEGF agent ranibizumab (Lucentis; Novartis (Basle, Switzerland) and Genentech (San Francisco, CA, USA) was cost effective. ${ }^{8}$ At the same time, guidance from the College clarified treatment recommendations. ${ }^{9}$ Thus commissioners of NHS care that is primary care trusts in England and local health boards in Wales have had a duty to commission such care for AMD patients from late 2008, and NHS hospitals have had a duty to comply with the NICE treatment guidelines. As wet-AMD is a common condition and as treatment requirements are frequent, this innovation has consequently required ophthalmic departments to cope with a significant volume of new activity. In a survey of ophthalmology departments undertaken in 2009, the College found there are considerable issues with the provision of anti-VEGF injection therapy in the NHS. ${ }^{10}$ The potential for sub-optimal clinical outcomes is real. Significant vision can be lost in a short time if wet AMD is not treated, ${ }^{11}$ and this can have a huge impact on independence and quality of life for patients. ${ }^{12}$

Following several influential reports on patient safety, learning from clinical failure or incident is now widely regarded as a core principle underpinning improvement in patient safety. ${ }^{13}$ The National Patient Safety Agency (NPSA) (http://www.npsa.nhs.uk) was thus initiated. A patient safety incident (PSI) is considered by the NPSA as an unintended or unexpected incident, which could have or did lead to harm for one or more patients. This is also referred to as an adverse event/incident or clinical error and includes 'near misses'. The NPSA includes a system for logging and gathering patient safety incidents (PSIs) at national level following local reporting. NHS organizations in England and Wales now forward local PSI reports to a national reporting and learning system (NRLS) repository database at the NPSA. Direct reporting to the NRLS is also possible. ${ }^{14}$ Following a Department of Health review in July 2010, the NPSA will be abolished and it is proposed that some of its functions will be transferred to a Patient Safety subcommittee of the new NHS Commissioning Board. ${ }^{15}$

Following the NICE guidance on wet-AMD treatment in 2008 and in the light of the College's concerns in 2009 about development of and provision of services for patients in the modern anti-VEGF era, we reviewed PSI reports on the NRLS database at the NPSA. We sought to identify reported incidents in anti-VEGF treatments in ophthalmic care. We aspired to identify any themes in these reports and to propose, if possible, measures to improve care.

\section{Patients and methods}

NHS providers in England and Wales report PSIs to the NPSA using local electronic submission processes. The information reported includes; clinical specialty, staff involved, location and time of the incident, degree of patient harm, and free text description of the incident. All submitted PSI reports are made anonymous within the NRLS database. Access to review an NRLS search was granted to one of the authors (SPK). The intention of this project was to identify incidents related to anti-VEGF treatments.

A search of the NRLS database by keyword was undertaken in June 2010. All anti-VEGF-related incidents reported from 2003 to the database up to and including June 2010 were included. First, the free text fields were searched for instances of any of the terms: ranibizumab, Lucentis; bevacizumab (Avastin, Roche (Basle, Switzerland) and Genentech) pegaptanib (Macugen, Pfizer, New York, NY, USA) and 'injection' and/or ophthalmology as area of care. Spelling mistakes or wild cards of these words were also considered.

All incident reports so retrieved from the NRLS database were reviewed. Thematic analysis of such cases as reported was undertaken. Our analysis was based on the narrative details provided in such reports only.

\section{Results}

The NRLS database held circa 5.5 million incident reports on the 16 June 2010, of which 26740 records were reported as related to the specialty of ophthalmology. Of these PSI reports, 166 cases/incidents were found relevant and where an anti-VEGF ophthalmic medication agent was mentioned in the report. The study period was from the initial roll out of the NRLS system throughout 2003 and until 16 June 2010. Analysis of the 166 PSIs was undertaken with a view to identify the themes or sources of potential error. Table 1 provides the principal reasons by theme for the anti-VEGF PSI reports. Multiple causal factors were not reported or specifically identifiable on any incident reports. Broadly speaking, where a theme was discernable, safety issues included: infection and inflammation problems; delay in referral, treatment or follow-up; medication availability and mix-ups; problems matching correct patient and to laterality. In our opinion, several of these matters reported revealed themes, which may have preventable measures. Table 2 provides examples of PSI reports. The text of the PSI report and grade of incident severity provided are as reported. Table 3 provides incidents reported by anti-VEGF medication agent and year. Our suggestions for possible measures for prevention or mitigation are presented in Table 4 . 
No time factors were discernable from PSI reports. No factors related to type of staff present (ie, rotating or locum or permanent staff) were discernable from the PSI reports. In all, 10 PSIs were graded by the reporters as 'severe' and 23 as 'moderate' harm. A total of 111 were

Table 1 Thematic analysis of anti-VEGF patient safety incident reports. $N=166$ reports

\begin{tabular}{ll}
\hline Thematic analysis & Number \\
\hline
\end{tabular}

\section{Treatment delay}

Endophthalmitis/inflammation

45

Wrong medication

Wrong patient

Wrong eye

Wrong dose

Prescription error and medication wasted

Missing clinical records

Wrong appointment

Scheduling problem

Treatment complication

Other graded 'low' or 'no' harm. There were no 'near miss' incidents reported. No deaths were reported. Incident dates: 4 reports were in 2006; 11 in 2007; 40 in 2008; 75 in 2009, and 36 in 2010 (up to middle of June 2010). Of the 16 cases of endophthalmitis/severe inflammation reported, 2 were associated with bevacizumab injection and 14 with ranibizumab injection. There were no anti-VEGF reports in ophthalmic care in 2003-2005, and these agents were not then available to ophthalmologists.

Table 3 Anti-VEGF medication incidents reported by year

\begin{tabular}{lccc}
\hline Year & Ranibizumab & Bevacizumab & Pegaptanib \\
\hline 2006 & 3 & 1 & 0 \\
2007 & 6 & 5 & 0 \\
2008 & 29 & 11 & 0 \\
2009 & 58 & 16 & 1 \\
$2010^{\text {a }}$ & 29 & 7 & 0 \\
Total & 125 & 40 & 1 \\
\hline
\end{tabular}

${ }^{\mathrm{a} N o t e: ~ 6-m o n t h s ~ d a t a ~ o n l y ~ f o r ~} 2010$.

Table 2 Free text reports; examples from selected PSI reports by theme

\begin{tabular}{|c|c|c|}
\hline Incident theme & Incident text as reported & $\begin{array}{l}\text { Incident severity as } \\
\text { reported }\end{array}$ \\
\hline Endophthalmitis & $\begin{array}{l}\text { - Patient admitted following Avastin injection (date stated) to operating theatre } \\
\text { for right vitreous tap with antibiotics - repeated on (another date stated) and } \\
\text { may need further surgery. }\end{array}$ & Severe \\
\hline \multirow[t]{2}{*}{ Wrong injection } & $\begin{array}{l}\text { Patient seen by consultant in clinical room after visual acuity had been } \\
\text { checked. Patient was due for second Lucentis injection. Consultant then saw } 3 \\
\text { more patients. Patient then taken into AMD room for procedure and } \\
\text { consented by consultant. Prepared for procedure and injected left eye. Health } \\
\text { care assistant came in and pointed out wrong eye but already injected. Patient } \\
\text { escorted to waiting area. }\end{array}$ & Low \\
\hline & $\begin{array}{l}\text { - } 0.5 \mathrm{ml} \text { intravitreal lidocaine given in error, thinking it was the Lucentis } \\
\text { injection syringe. Afterwards intravitreal Lucentis injection given as normal. }\end{array}$ & No harm \\
\hline \multirow[t]{2}{*}{$\begin{array}{l}\text { Medication supply } \\
\text { and storage }\end{array}$} & $\begin{array}{l}\text { - The pharmacy has only one available Lucentis injection for } 2 \text { cases. } \\
\text { Apparently the ordered drug has not come in time for case this morning } \\
\text { hence we have to cancel one patient. }\end{array}$ & Moderate \\
\hline & $\begin{array}{l}\text { - Drug fridge was off all weekend and noted at } 11: 30 \text { to be at } 20 \mathrm{C} \text {. The fridge } \\
\text { temperature is checked daily and was in working order on the previous } \\
\text { Friday. } 2 \text { syringes of ranibizumab had been issued on Monday morning } \\
\text { before the fridge temperature had been discovered. } 2 \text { patients were given the } \\
\text { injection. }\end{array}$ & No harm \\
\hline \multirow[t]{3}{*}{ Error in follow up } & $\begin{array}{l}\text { - Patient having } 3 \text { initial injections of Lucentis, put down for review one month } \\
\text { after the } 3 \text { rd but was not given appointment till nearly } 3 \text { months after this. He } \\
\text { needed monthly treatment but his follow up was not on time due to busy } \\
\text { clinics. }\end{array}$ & Moderate \\
\hline & $\begin{array}{l}\text { - } 40 \text { Patients identified who had received intravitreal ranibizumab therapy } \\
\text { earlier than the recommended } 28 \text { day interval since (date stated). Patients } \\
\text { were identified retrospectively and to date there has been no adverse medical } \\
\text { outcome. }\end{array}$ & None \\
\hline & $\begin{array}{l}\text { Patient attended AMD services on (date stated). Diagnosis bilateral AMD. } \\
\text { Plan of treatment right and left Lucentis intra vitreal injection. Left eye to be } \\
\text { treated first. At this stage left eye was treatable. Patient put on waiting list } \\
\text { next available date being } 26 \text { days following. On this day left eye visual } \\
\text { activity reduced to } 8 \text { letters only therefore too much vision lost and treatment } \\
\text { no longer viable. Only treatment could be given to the right eye. }\end{array}$ & Severe \\
\hline
\end{tabular}

Reports are largely in the unedited words of reporters. Any identifiable dates or place names have been removed. 
Table 4 Authors' suggestions for reducing anti-VEGF incidents

- Providers and commissioners of wet-AMD clinical services should plan services based on realistic estimates of wet-AMD incidence.

- Follow best evidence in anti-VEGF medication care.

- Maintain high standard of aseptic technique for intra-vitreal injections.

- Consider electronic patient records, electronic prescriptions, and audit tools.

- Consider pre-injection checklist and 'time out', especially for high volume and/or mixed surgical schedules/lists.

- Ensure adequate stock of anti-VEGF medication is in place in injection facility.

- Alarmed refrigerators for anti-VEGF agent storage and reliable medication supply services are vital.

\section{Discussion}

The NRLS database contained close to 27000 PSI reports related to ophthalmology care from England and Wales by the middle of June 2010.

The data show instances of the wrong patients and wrong eyes receiving intra-vitreal anti-VEGF injections. Medical and surgical confusions (ie, wrong patient, wrong medication, wrong site or side surgery, wrong procedure, or implant) are an infrequent but long recognized and important and preventable cause of patient morbidity and complaint in general, and relevant to ophthalmic surgeons. ${ }^{16,17}$

Under-reporting of PSIs is widespread and recent studies found that only a minority of NHS incidents are reported. ${ }^{18}$ Medical staff have barriers to incident reporting and reporting is often nurse-led. ${ }^{19-21}$ Thus, this review almost certainly underestimates the number of anti-VEGF incidents occurring in NHS care during the study period, although it is likely to be indicative of the types of adverse event and near miss which may occur. A weakness of our retrospective review from a data set is that clinical detail of the cases on the data set is scant, and root causation of misadventures is not provided within reports. PSI causation is not described by reporters in a standard format, or at all. Rather PSI reports are provided in free text by the reporter and frequently contain anecdote-based opinion. Furthermore, the severity of patient harm is self-declared by the PSI reporter. The NPSA's guidance '7 Steps to Patient Safety' provides a framework for incident reporting and it includes a classification of severity grading. ${ }^{22}$ We cannot tell if this was adhered to. There were cases where patients suffered injections into the wrong eye, but the degree of harm from the original PSI was labeled as 'no harm'. Another potential weakness of the present review is that adverse drug reactions (ADRs) in the UK are reported to the Medicines and Healthcare products
Regulatory Agency (MHRA) through the Yellow Card Scheme (http:/ / www.yellowcard.gov.uk) rather than via patient safety reports. Thus our study does not capture any ADR that may have been reported via that mechanism or indeed directly to medication manufacturers or license holders. Nevertheless, this review demonstrates that it is also possible in part to track or monitor patient safety issues arising from a new treatment/procedure introduced into care from about 2006 onwards. Using similar methods of analysis of the NRLS has been undertaken to explore safety reports of certain anesthetic agents. ${ }^{23}$

Broadly speaking, safety issues we found included: infection and inflammation problems; delays in treatments; medication availability and mix-ups; problems matching correct patient/eye, and laterality. Many of these are a reflection of the challenges of clinical care such as avoiding healthcare-associated infections and matching correct medications, and data to correct patients. We found similar problems of confusion in ophthalmic care in a review of intra-ocular lens implant incidents reported via the NRLS. ${ }^{24}$ Mix-ups causing harm when medications are injected into the wrong part of the eye are a microcosm of medication errors. The inadvertent intra-vitreal injection of cefuroxime - perhaps intended for sub-conjunctival injectioninstead of ranibizumab (Lucentis) intended for intravitreal injection was reported and led to retinal toxicity and visual loss. Likewise, inadvertent intra-vitreal injection of lidocaine - intended for ocular surface anesthesia - instead of ranibizumab (Lucentis) intended for intra-vitreal injection in another two incidents were reported.

This review cannot propose solutions to all the service delivery issues of the introduction of novel treatments. Much service development work is underway on attempting to improve services for wet-AMD patients by the College, patient support groups, and the National Eye Care Plan. However, certain signals emerge from this review and from which some lessons can be learned. Firstly, the widespread recent introduction of intravitreal injections has created a new potential source of healthcare acquired endophthalmitis and intra-ocular inflammation. The reported incidence of endophthalmitis per injection in various studies ranged from 0.02 to $1.9 \%{ }^{3-5,25-29}$ Several of the cases of infection/ endophthalmitis in such publications were attributed to protocol violations, chief of which was not using an eye lid speculum at the time of injection. ${ }^{25}$ With better attention to aseptic technique later in the early key clinical trials, the incidence of post-injection inflammation and infection decreased. A recent metaanalysis of the US literature from 2005 to 2009 reported 52 cases of endophthalmitis after 105536 intra-vitreal 
anti-VEGF injections $(0.049 \%){ }^{30}$ Injection room facilities have been developed for intra-vitreal injection at ophthalmic facilities in the UK. We understand informally from peer discussions that the cases of infectious intra-ocular inflammation/endophthalmitis in NHS care in 2009, may have been due to breaches in asepsis techniques or infrastructure in injection room facilities in two centres. We understand informally that following changes of practise that such episodes have reduced/stopped at those facilities (Discussion at Medical Retina Group Annual Meeting, Oxford, 2010). Intra-vitreal injections are an invasive procedure and are not risk free, and must be taken seriously by all concerned. We stress that eye-care teams undertaking intra-vitreal injections need to be vigilant concerning aseptic technique. The requirement for frequent injections makes this cumulative risk of intra-ocular infection relevant to individual patients. Results of the British Ophthalmic Surveillance Unit (BOSU) study of endophthalmitis cases over the same time period following anti-VEGF injections are awaited with interest. $^{31}$

Second, on a service provision level the frequency of anti-VEGF injections or assessments required, to achieve good clinical outcomes in wet-AMD, requires a commitment to commission a service with adequate clinical manpower/infrastructure. It is necessary in our opinion, based on the key clinical trials to ensure that the frequent intra-vitreal injections or clinic assessments required are provided safely and in a timely fashion (usually monthly), in order to provide continuing protection against visual loss. The present patient safety incident reports, highlight capacity has been problematic at times in hospital eye services in England and Wales. This mirrors the concerns of the College's audit on provision of such services in the UK in $2009 .{ }^{10} \mathrm{We}$ suggest that commissioners and providers agree appropriate service level agreements to ensure that AMD patients receive the appropriate care and in compliance with the relevant NICE guidance. Support from both hospital management and commissioners is needed to ensure such arrangements. Monitoring of patient clinical outcomes is also of merit to ascertain if satisfactory outcomes are being achieved, in what is a challenging new pressure on ophthalmology departments.

Third, many errors with anti-VEGF treatments reported were not complex technological matters or organizational issues. Many problems occurred due to missing clinical records, prescription mix-ups, and communication breakdowns. Again these are a mirror of organizational patient safety challenges.

Fourth, it is important in our experience to maintain a smooth flow during treatment sessions and to keep distractions or interruptions at the lowest possible level.
The Patient Safety First campaign ${ }^{32}$ and many similar initiatives recommend both a team brief before surgery and taking 'time out' and a checklist before starting the surgical procedure. The ever-present risk of wrong patient or wrong eye errors in the high-throughput environment of a wet-AMD injection service requires constant vigilance.

Fifth, PSI reports of lack of medication availability and refrigeration failures reflect the relatively high costs of anti-VEGF medications, and the need to order these agents and store them in a refrigerator at a temperature of $2-8{ }^{\circ} \mathrm{C}$. In our opinion, this high medication cost may have stimulated reporting by staff whenever supply problems or waste of such medications occurred. The use of refrigerators with temperature alarms and logs is of merit in the storage of anti-VEGF medication agents. Reliable supply chains for medication delivery to providers at the correct temperature are critical. We have thus suggested that assistance - including replacement of wasted medications - from the pharmaceutical suppliers or manufactures to hospital pharmacies be improved upon and await developments.

In relation to systemic safety matters, few reports located were relevant. One report of stroke, other of subdural haemorrhage, and another of possible myocardial infarction following intra-vitreal treatments occurred. Although these are potential side effects of VEGF inhibitor, their proximity to treatment does not necessarily indicate causality. No deaths were reported. Patient safety incident reporting is not an appropriate tool to undertake pharmacovigilance surveillance. Pharmacovigilance is defined by the World Health Organisation as the science and activities relating to the detection, assessment, understanding and prevention of adverse effects or any other drug-related problem' ${ }^{33}$ This is topical in patient care as bevacizumab is not approved for intra-vitreal injection, but is often so used. ${ }^{34}$ The present review does not add any additional specific pharmacovigilance signals to those already known in relation to the safety profile of any of the intra-vitreal anti-VEGF medication treatments, approved or un-licensed. Systemic safety signals may perhaps be detectable from healthcare resource usage databases and as signaled in the recent review of Medicare claims following treatment of AMD. ${ }^{35}$ In the UK suspected adverse drug reactions (ADR), both systemic and ocular, should be reported to the Medicines and Healthcare products Regulatory Agency (MHRA). ADRs should be reported for both licensed and unlicensed indications, to allow effective monitoring of the safety of medicines in real-life practice. It would be of interest to triangulate our findings with ADR reports on the MHRA's databases. Spontaneous ADR reporting is also thought be an underestimate of ADR events. ${ }^{36}$ It should also be 
recognized that medication safety is more than the monitoring, detection, and assessment of ADRs and that spreading good practise, service improvement, and learning from safety reports is important to improving clinical outcomes.

Moving forwards, as anti-VEGF agents also improve clinical outcomes in other retinal patients, such as those affected by diabetic macular edema $(\mathrm{DMO})^{37}$ or retinal venous occlusions (RVO), ${ }^{38}$ these further treatment developments and emerging guidelines ${ }^{39}$ are likely to put further pressures on retinal services and intra-vitreal injection services. Lessons from anti-VEGF use during the roll out phase of such medications in AMD care in England and Wales may assist the extra challenges for DMO and RVO patient management now on the horizon.

In conclusion, this retrospective review of PSIs as reported to a national database demonstrates that learning from such a database has some merit in supporting provision of anti-VEGF medication care in ophthalmology. We encourage ophthalmic teams to undertake more patient safety reporting, both PSI reporting and ADR reporting, in the present anti-VEGF era. The Royal College of Ophthalmologists has provided guidance on patient safety for ophthalmic teams. ${ }^{40}$

\section{Summary}

What was known before

- Although infrequent, patient safety issues in ophthalmology occur.

- Patient safety issues and mix-ups are a potent area of complaint and litigation.

- NHS patient safety incidents from England and Wales are being collected into a central database.

What this study adds

- A national database of patient safety incident reports can provide learning to staff involved in care of retinal patients with anti-VEGF medications.

- Suggestions to reduce anti-VEGF incidents and based on incident reports received from the service are provided.

\section{Conflict of interest}

SP Kelly is Chairman of Quality and Safety Sub-Committee at the Royal College of Ophthalmologists. This is an unpaid position. He has declared received consulting fees for attending advisory board meetings and travel support from Novartis, Allergan and Pfizer.

\section{Acknowledgements}

We thank Michael Surkitt-Parr at the NPSA for undertaking database searches. We thank Lucy Titcomb, Barbara McLaughlin, David Silverman, Richard Smith and Suzette Woodward for comments on a draft of the manuscript.

\section{Author Contributions}

SPK and AB are responsible for drafting this manuscript. SPK is the guarantor of this article.

\section{Ethical matters}

A data sharing undertaking between SPK and the NPSA was undertaken in line with data protection procedures at the NPSA. No identifiable patient data was viewed in data analysis.

\section{Provenance and peer review}

Not commissioned; externally peer reviewed.

\section{Funding}

No special funding.

\section{References}

1 Owen CG, Fletcher AE, Donoghue M, Rudnicka AR. How big is the burden of visual loss caused by age related macular degeneration in the United Kingdom? $\mathrm{Br} J$ Ophthalmol 2003; 87: 312-317.

2 Bunce C, Xing W, Wormald R. Causes of blind and partial sight certifications in England and Wales: April 2007-March 2008. Eye 2010; 24: 1692-1699.

3 Gragoudas ES, Adamis AP, Cunningham Jr ET, Feinsod M, Guyer DR, for the VEGF Inhibition Study in Ocular Neovascularization Clinical Trial Group. Pegaptanib for neovascular age-related macular degeneration. $N$ Engl J Med 2004; 351: 2805-2816.

4 Rosenfeld PJ, Brown DM, Heier JS, Boyer DS, Kaiser PK, Chung CY et al. Ranibizumab for neovascular age-related macular degeneration. $N$ Engl J Med 2006; 355: 1419-1431.

5 Brown DM, Kaiser PK, Michels M, Soubrane G, Heier JS, Kim RY et al. Ranibizumab vs verteporfin for neovascular age-related macular degeneration. $N$ Engl J Med 2006; 355: 1432-1444.

6 Chakravarthy U, Soubrane G, Bandello F, Chong V, CreuzotGarcher C, Dimitrakos II SA et al. Evolving European guidance on the medical management of neovascular age related macular degeneration. $\mathrm{Br} J$ Ophthalmol 2006; 90: 1188-1196.

7 Royal College of Ophthalmologists. Commissioning Contemporary AMD Services: a Guide for Commissioners and Clinicians. Royal College of Ophthalmologists: London, 2007. http://www.rcophth.ac.uk/documents.asp?section= $39 \&$ sectionTitle $=$ Publications\&let $=$ C\&page $=7$.

8 National Institute for Health and Clinical Evidence. NICE Technology Appraisal Guidance TA155, Ranibizumab and Pegaptanib for the Treatment of Age-related Macular Degeneration. National Institute for Health and Clinical Evidence: London, 2008. http://www.nice.org.uk/ nicemedia/pdf/TA155guidance.pdf.

9 Amoaku W. Ranibizumab: The clinician's guide to commencing, continuing, and discontinuing treatment. Eye 2009; 23: 2140-2142.

10 Royal College of Ophthalmologists. AMD Services Survey. Royal College of Ophthalmologists: London, 2009. 
http:/ / www.rcophth.ac.uk/page.asp?section $=295 \&$ section Title $=$ AMD + Services + Survey.

11 Bressler NM. Photodynamic therapy of subfoveal choroidal neovascularization in age-related macular degeneration with verteporfin: two-year results of 2 randomized clinical trials. TAP report number 2. Arch Ophthalmol 2001; 119: 198-207.

12 Mitchell J, Bradley C. Quality of life in age-related macular degeneration: a review of the literature. HealthQual of Life Outcomes 2006; 4: 97.

13 World Health Organization. WHO Draft Guidelines on Adverse Event Reporting and Learning Systems. World Health Organization Press: Geneva, Switzerland, 2005. http:/ / www.who.int/patientsafety/events/05/Reporting Guidelines.pdf.

14 National Patient Safety Agency. Report a Patient Safety Incident Here. National Patient Safety Agency: London. http://www.npsa.nhs.uk/patientsafety/reporting.

15 Department of Health. Review of Arm's Length Bodies to Cut Bureaucracy. Depart of Health: London, 2010. http:// www.dh.gov.uk/en/MediaCentre/Pressreleases/DH_117844.

16 Traquair H. Removal of the wrong eye. Br J Ophthalmol 1947; 31: 8-12.

17 Simon JW, Ngo Y, Khan S, Strogatz D. Surgical confusions in ophthalmology. Arch Ophthalmol 2007; 125: 1515-1522.

18 Dixon-Woods M. Why is patient safety so hard? A selective review of ethnographic studies. J Health Serv Res Policy 2010; 15: 11-16.

19 Vincent CN, Stanhope N, Crowley-Murphy M. Reasons for not reporting adverse incidents: an empirical study. J Eval Clin Pract 1999; 5: 13-21.

20 Lawton R, Parker D. Barriers to incident reporting in a healthcare system. Qual Saf Health Care 2002; 11: 15-18.

21 Evans SM, Berry JG, Smith BJ, Esterman A, Selim P, $\mathrm{O}$ 'Shaughnessy $\mathrm{J}$ et al. Attitudes and barriers to incident reporting: a collaborative hospital study. Qual Saf Health Care 2006; 15: 39-43.

22 National Patient Safety Agency. Seven Steps to Patient Safety. National Patient Safety Agency: London, 2005. http:// www.nrls.npsa.nhs.uk/resources/collections/ seven-steps-to-patient-safety.

23 Arnot-Smith J, Smith AF. Patient safety incidents involving neuromuscular blockade: analysis of the UK National Reporting and Learning System data from 2006 to 2008. Anaesthesia 2010; 65: 1106-1113.

24 Kelly SP, Jalil A. Wrong intraocular lens implant; learning from reported patient safety incidents. Eye 2011; 25: 730-734.

25 Scott IU, Flynn Jr HW. Reducing the risk of endophthalmitis following intravitreal injections. Retina 2007; 27: 10-12.

26 Fintak DR, Shah GK, Blinder KJ, Regillo CD, Pollack J, Heier JS et al. Incidence of endophthalmitis related to intravitreal injection of bevacizumab and ranibizumab. Retina 2008; 28(10): 1395-1399.

27 Mason III JO, White MF, Feist RM, Thomley ML, Albert MA, Persaud TO et al. Incidence of acute onset endophthalmitis following intravitreal bevacizumab (Avastin) injection. Retina 2008; 28(4): 564-567.

28 Pilli S, Kotsolis A, Spaide RF, Slakter J, Freund KB, Sorenson $\mathrm{J}$ et al. Endophthalmitis associated with intravitreal anti-vascular endothelial growth factor therapy injections in an office setting. Am J Ophthalmol 2008; 145: 879-882.

29 Johnson D, Hollands H, Hollands S, Sharma S. Incidence and characteristics of acute intraocular inflammation after intravitreal injection of bevacizumab: a retrospective cohort study. Can J Ophthalmol 2010; 45: 239-242.

30 McCannel CA. Meta-analysis of endophthalmitis after intravitreal injection of anti-vascular endothelial growth factor agents: Causative organisms and possible prevention strategies. Retina 2011; 31: 654-661.

31 Tey A, Lyall D, Foot B, Virdi M, Roxburgh S, MacEwan C. Post intravitreal anti-VEGF endophthalmitis (PIAE) in the United Kingdom: Incidence, Features and Outcomes, Conference Abstract; 24 May 2011. Royal College of Ophthalmologists Annual Scientific Congress: Birmingham.

32 Patient Safety First Campaign. Quick Guide to Briefing. Patient Safety First Campaign: London, 2010. Available at http://www.patientsafetyfirst.nhs.uk/ashx/ Asset.ashx?path $=/$ Intervention-support/Quick\% 20guide $\% 20$ to $\% 20$ briefngs\%20and\%20debriefings.pdf.

33 WHO Policy Perspectives on Medicines: World Health Organization. Looking at the Pharmacovigilance: Ensuring the Safe Use of Medicines. WHO: Geneva, 2004. Available from: http://whqlibdoc.who.int/hq/2004/WHO_EDM_ 2004.8.pdf.

34 Schmucker C, Ehlken C, Hansen LL, Antes G, Agostini HT, Lelgemann M. Intravitreal bevacizumab (Avastin) vs ranibizumab (Lucentis) for the treatment of age-related macular degeneration: a systematic review. Curr Opin Ophthalmol 2010; 21: 218-226.

35 Curtis LH, Hammill BG, Schulman KA, Cousins SW. Risks of mortality, myocardial infarction, bleeding, and stroke associated with therapies for age-related macular degeneration. Arch Ophthalmol 2010; 128(10): 1273-1279.

36 Fletcher AP. Spontaneous adverse drug reaction reporting vs event monitoring: a comparison. J R Soc Med 1991; 84(6): 341-344.

37 Massin P, Bandello F, Garweg JG, Hansen LL, Harding SP, Larsen $\mathrm{M}$ et al. Safety and efficacy of ranibizumab in diabetic macular edema (RESOLVE Study): a 12-month, randomized, controlled, double-masked, multicenter phase II study. Diabetes Care 2010; 33: 2399-2405.

38 Karia N. Retinal vein occlusion: pathophysiology and treatment options. Clin Ophthalmol 2010; 4: 809-816.

39 The Royal College of Ophthalmologists. Retinal Vein Occlusion (RVO) Interim Guidelines. The Royal College of Ophthalmologists: London, 2010. http://www.rcophth. ac.uk $/$ page.asp? section $=451 \&$ sectionTitle $=$ Clinical + Guidelines.

40 The Royal College of Ophthalmologists. Patient Safety in Ophthalmology. The Royal College of Ophthalmologists: London, 2011. http://www.rcophth.ac.uk/core/ core_picker $/$ download.asp?id $=852 \&$ filetitle $=$ Patient + Safety + in + Ophthalmology + February +2011 .

This work is licensed under the Creative Commons Attribution-NonCommercial-Share Alike 3.0 Unported License. To view a copy of this license, visit http://creativecommons.org/licenses/by-nc-sa/3.0/ 